\title{
Estimation of Lightning Overvoltage in Signalling Equipment on Electrified Railways
}

\author{
Yuto ONO \\ Takuya NOMURA \\ Hiroyuki FUJITA \\ Hideki ARAI \\ Signalling Systems Laboratory, Signalling and Transport Information Technology Division
}

\begin{abstract}
Railway signalling systems have been damaged by lightning. Therefore, effective and economical lightning protection measures are necessary for railway signalling systems. To analyze lightning risk and study countermeasures against lightning damage, the authors therefore observed lightning overvoltage in electrified railway signal cables, electrical power lines and rails. Based on the result of these observations, the correlation between lightning overvoltage and lightning conditions was clarified, a methodology for estimating the probability of lightning hazards occurring was proposed, and it was found that according to statistics, there was no significant variation in overvoltage observed between electrified and nonelectrified sections of railway.
\end{abstract}

Keywords: lightning surge, signal cable, electrified section, ground voltage, line voltage

\section{Introduction}

Railway signalling systems are sometimes damaged by lightning. Railway signalling systems have made remarkable progress in recent years with their components becoming increasingly compact and multi-functional due to the adoption of microcomputers and a wide range of other electronic devices. However, circuit burnout, system failure and other types of lightning damage frequently affects signalling systems because these electronic devices are easily damaged by lightning surges. It is estimated that $70 \%$ of all disruptions caused by lightning on the Japanese railways involve signalling equipment. Traffic disruptions have an impact on society, so effective and economical lightning protection measures are necessary for railway signalling systems.

However, countermeasures against lightning damage to railway signalling systems are often implemented through trial and error. Although this is not effective, for the moment it is the only method available, since overvoltage caused by lightning has not yet been quantitatively analyzed.

Lightning overvoltage in signal cables and rails of a non-electrified section was observed from 2010 to 2013, in order to quantitatively analyze lightning risk [1]. For a deeper analysis of lightning risk, a similar observation was conducted of an electrified section of line from 2015 to 2016. This paper is a report of these observations and presents the results of the subsequent analysis.

\section{Observation methodology}

\subsection{Observing field}

Observations of lightning overvoltage in cables and rails were made on an electrified and quadruple track railway line. The observation period spanned the summers of 2015 (from May 22nd to October 22nd) and 2016 (from May 23rd to October 22nd).

\subsection{Constitution of the Observing System}

The constitution of the observing system is shown in Fig. 1. This system was used to observe lightning overvoltage (ground voltage) in the core of signal cables, rails, signalling system power lines and overhead power lines used as a commercial electrical power supply cable for activating the measuring system. The signal cable had 4 cores, a length of $466 \mathrm{~m}$, with a core area of 1.25 square millimeters. It was laid only for this experiment, so it was not connected to the actual signalling system. When a lightning overvoltage over or equal to the trigger level in the observing system (signal cable: +/- $156 \mathrm{~V}$, power line for signalling system: +/- $479 \mathrm{~V}$, rail: +/- $313 \mathrm{~V}$, overhead commercial power line: $+/-625 \mathrm{~V}$ ) occurred in one of these observation channels, the whole waveform of the voltage was recorded. The length of the waveform was $102.4 \mu \mathrm{s}$ (50 ns x 2048 samples) and the time of the day obtained from the GPS antenna was also recorded.

Power line for signalling system (AC110V)

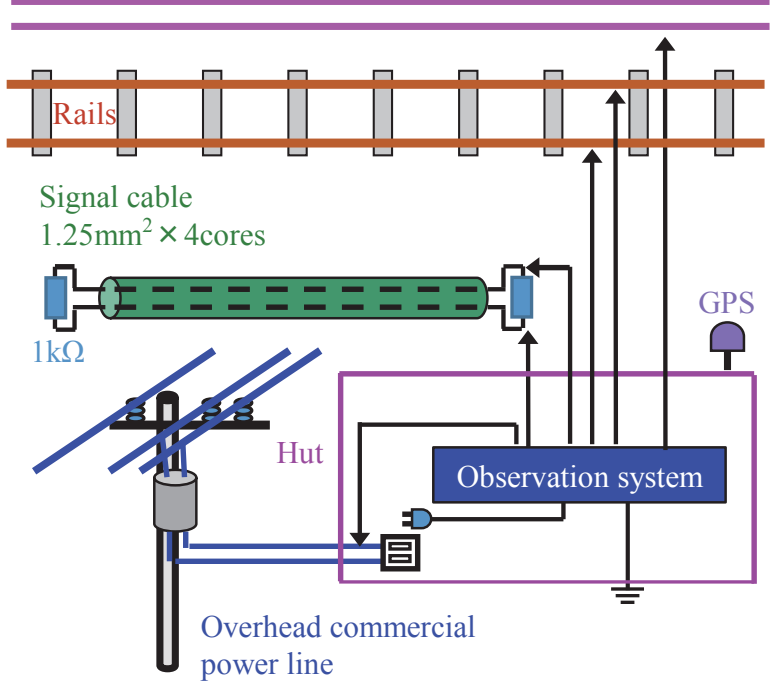

Fig. 1 Schema of the observation system 
At both the ends of the signal cable, $1 \mathrm{k} \Omega$ resistances were inserted between two cable cores. These resistances were used for simulating the electrical load of the signalling equipment. Terminal impedance is much higher than that of the cable, so the value of overvoltage is doubled by regular reflection at the end of the cable [2]. As a result, in this research, the value of overvoltage in the signal cable was reduced to a half of the actual data.

In this research, although the line voltage was not measured directly, the line voltage of the signal cable and the rail were given by the difference in ground voltage between the two cable cores or two rails.

\subsection{About lightning}

When lightning strikes, a strong impulsive electromagnetic field is generated, consisting of a static electric field, induction field and radiated electromagnetic field. The strength of each field is, if the distance of each field from the strike position is denoted by $r$, proportional to the minus third, the minus second and the minus first power of $r$ respectively. Consequently, in a position which is distant from spot where lightning struck, the radiated electromagnetic field is dominant.

Equation (1) stands for overvoltage generated by the radiated electromagnetic field [3]; therefore, the overvoltage is proportional to the current and inversely proportional to the distance. This paper refers to "the lightning current $(I)$ divided by the distance $(r)$, namely $I / r$ " as the "lightning condition" and analyzes the correlation between the lightning condition and the lightning overvoltage.

$$
V=A \cdot \frac{I}{r}
$$

$V$ : Value of the overvoltage [V], A: Constance, I: Lightning current [A], $r$ : Distance from the strike position [m]

The authors acquired $I$ and $r$ from the JLDN (Japan Lightning Detection Network). This network consists of 30 sensors installed across Japan. They detect the electromagnetic field produced from lightning strikes. Data from the sensors was used to calculate the position of the lightning strike and current. The data also includes the time of the strike obtained by GPS.

A check was run to detect which lightning generated overvoltage, by comparing the GPS time of the recorded waveforms of lightning overvoltage and the time of lightning acquired by the JLDN.

It should be noted that the number of lightning strikes acquired by the JLDN is estimated to represent over $90 \%$ of actual lightning strikes in summer. The error margin of the estimation of the strike position is roughly $500 \mathrm{~m}$. The estimated lightning current is about 1.32-2.06 times larger than the current actually measured [4]. The smallest unit of current is $1 \mathrm{kA}$. JLDN data does not include lightning current waveforms. If the current increases sharply, generated overvoltage is higher; this research however does not discuss the influence of differences in lightning waveforms on overvoltage.

\section{Results}

\subsection{Lightning characteristics}

During the observation period, lightning struck 1391 times in the area within a $10-\mathrm{km}$ radius of the observation point. Of these, 126 generated lightning overvoltage over or equal to the trigger level of the observation system.

Figure 2 shows the properties of the lightning. Distance $(r)$ is plotted on the horizontal axis, lightning current $(I)$ is plotted on the vertical axis, and lightning strikes which generated overvoltage higher than or equal to the trigger voltage are shown with the red circle marks and those generating a lower overvoltage are shown with blue cross marks. From Fig. 2, it can be said that the higher $I$ and the shorter $r$ are, the higher the possibility of lightning overvoltage exceeding the trigger level.

\subsection{Example of waveforms}

Figure 3 shows an example of overvoltage waveforms generated in a rail, a signal cable core, a signalling system power line and an overhead commercial power line. The overvoltage occurred on 5th August in 2016, at 20:10:42; I was $-32 \mathrm{kA}$, and $r$ was $0.598 \mathrm{~km}$; so $I / r$ was $54 \mathrm{kA} / \mathrm{km}$. Figure 4 shows the map of all the lightning strike positions on this date and the strike positions of the lightning corresponding to Fig. 3 is indicated by the text "Strike position."

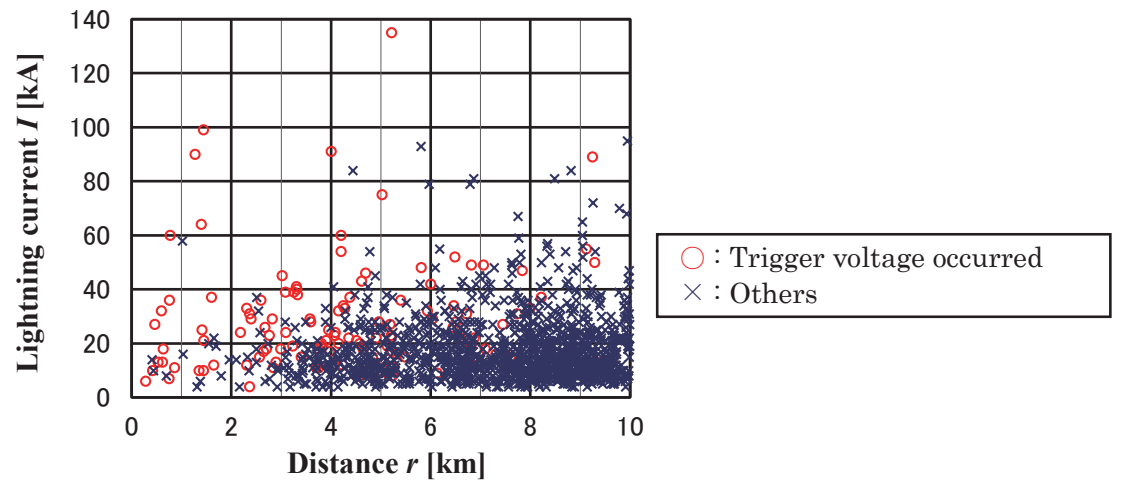

Fig. 2 Properties of lightning strokes 


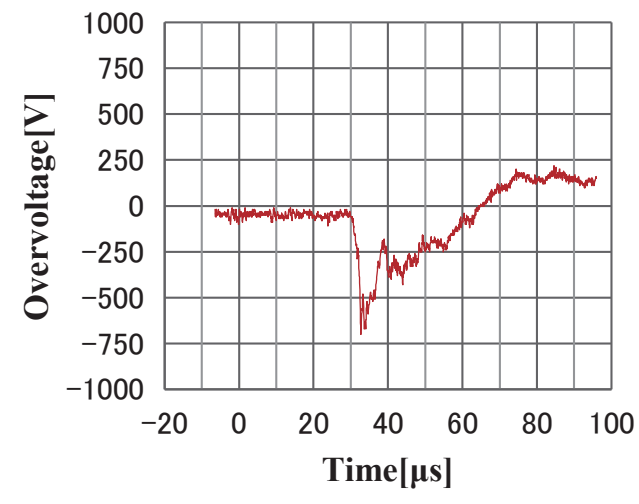

(a) Rail

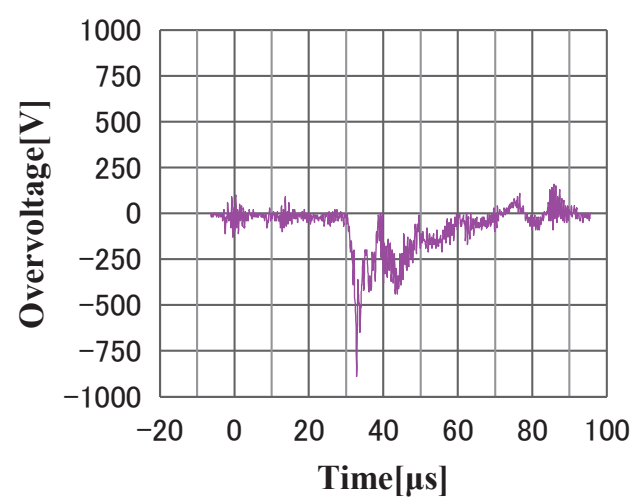

(c) Power line for the signalling system

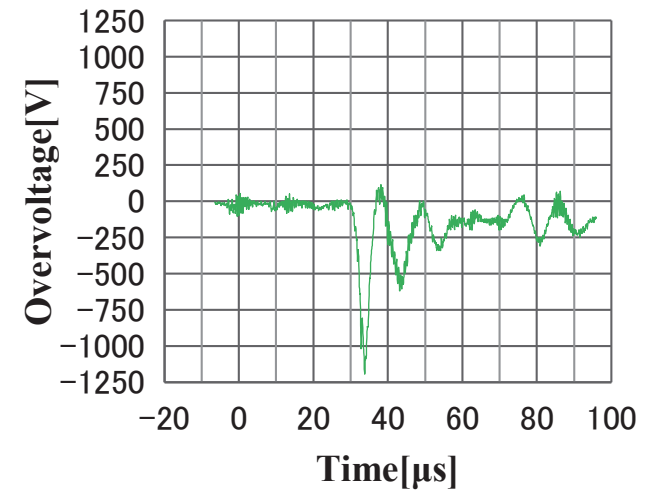

(b) Signal cable

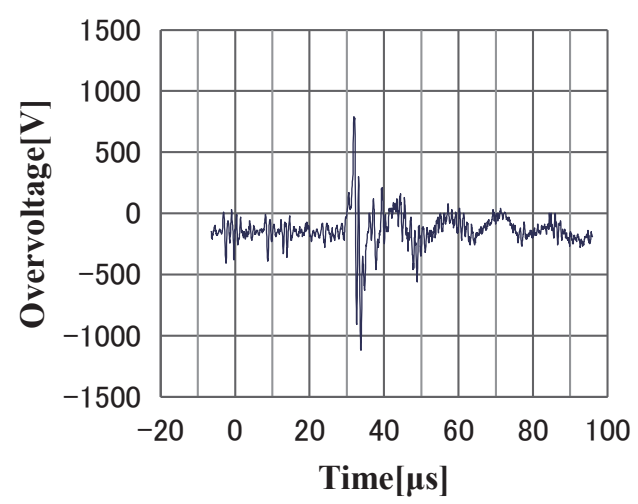

(d) Overhead commercial power line

Fig. 3 Example of lightning overvoltage waveforms

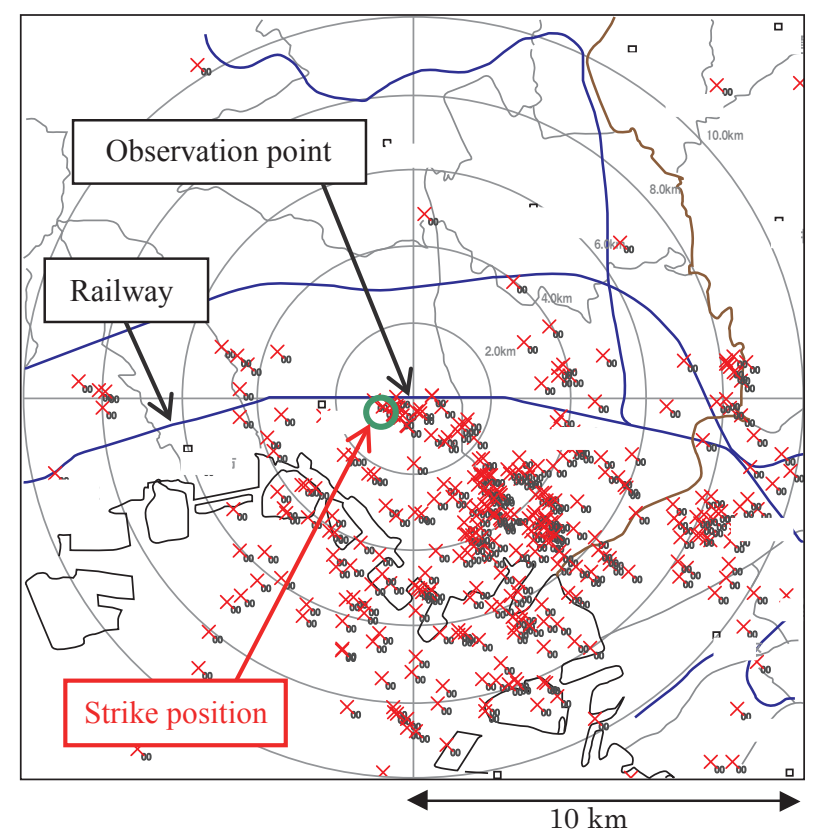

$\times:$ Strike position

Fig. 4 Lightning strike position map

\subsection{Correlation between lightning conditions and lightning overvoltage}

Figure 5 shows the lightning condition $[\mathrm{kA} / \mathrm{km}]$ and the maximum absolute values of lightning overvoltage $[\mathrm{kV}]$ generated in the rail, the signal cable core, the power line for the signalling system and the overhead commercial power line. As shown in this figure, it can be said that the higher the lightning condition, the higher the value of the lightning overvoltage. 


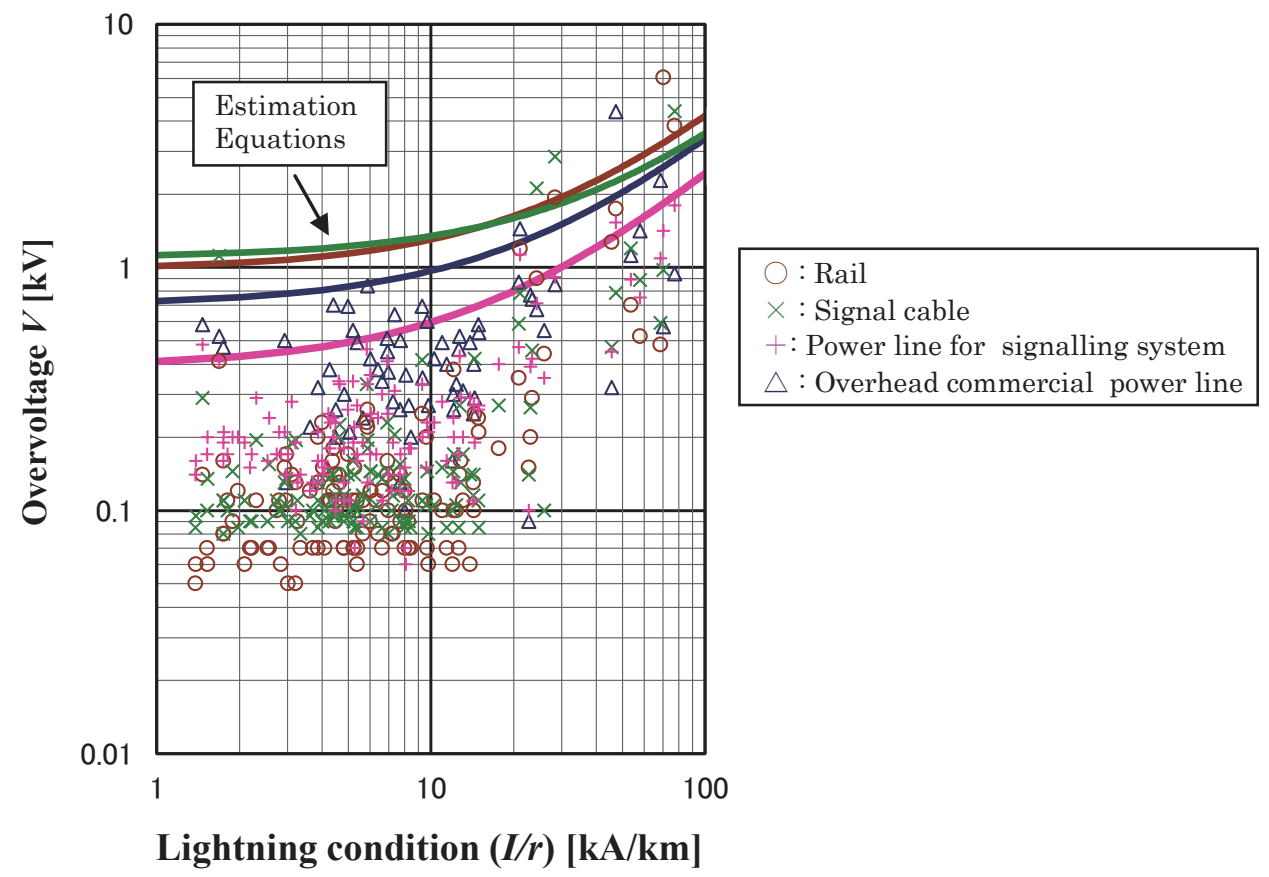

Fig. 5 Correlation between lightning conditions and lightning overvoltage

The four lines shown in Fig. 5 represent the "estimation equations." The area below this contains $97 \%$ of the plotted data, and the estimation equations make it possible to estimate the value of lightning overvoltage from the lightning conditions. The reason these equations do not include halves, as is often in the case with linear approximate equations, but account for $97 \%$ of the plotted data, is because the equations are formulated in a way which ensures that the estimated values are high enough thereby offering safer protection for signalling equipment. The estimation equations are shown in Table 1.

Table 1 Estimation Equations in Fig. 5

\begin{tabular}{ll}
\hline \multicolumn{1}{c}{ Subjects for overvoltage observation } & Estimation equations \\
\hline Rail & $V=0.032(I / r)+0.98$ \\
Signal cable & $V=0.025(I / r)+1.1$ \\
Power line for the signalling system & $V=0.021(I / r)+0.39$ \\
Overhead commercial power line & $V=0.027(I / r)+0.70$ \\
\hline \hline
\end{tabular}

\subsection{Estimation of lightning overvoltage from light- ning conditions}

It is postulated that signalling equipment with a surge breakdown voltage of $10 \mathrm{kV}$ is connected to the rail. According to the estimation equation of the rail, the lightning conditions that would generate an overvoltage that reaches $10 \mathrm{kV}$ would be $I / r=278 \mathrm{kA} / \mathrm{km}$; accordingly, if $I$ is $31 \mathrm{kA}$ and $r$ is less than $111 \mathrm{~m}$, the signalling equipment would be destroyed by lightning overvoltage because the overvoltage generated in the rail attained $10 \mathrm{kV}$.

Judging from the estimation equations for the signalling system power line and the overhead commercial power line, it is estimated that the overvoltage generated in the overhead commercial power line is higher than that generated in the power line for the signalling system. From this result, it can be said that the lightning hazard risk grows if the signalling system is activated by commercial power.

\subsection{Estimation of the probability of occurrence of the lightning hazards}

As mentioned in the preceding section, the lightning conditions that create a lightning hazard for signalling equipment are estimated using the estimation equations and the lightning resistance voltage of the signalling equipment.

The number of lightning hazards for signalling equipment connected to a rail, in other words, lightning strikes with a lightning condition over or equal to $278 \mathrm{kA} / \mathrm{km}$ can be calculated by (2) [1].

$$
N_{h}=N_{l} \int_{0}^{10} \frac{1}{1+(278 r / 31)^{2.6}} \cdot \frac{2 \pi r}{100 \pi} d r
$$

$N_{h}$ : The number of lightning hazards per year [times/year],

$N_{l}$ : The number of lightning strikes per year in the area within a $10-\mathrm{km}$ radius from the signalling equipment [times/year].

According to (2), if $N_{l}$ is 700 times/year, the corresponding number of lightning hazards per year is 0.22 times/ year. In fact, the signalling equipment around the observation point was destroyed once in 2016, which means that this estimation was not so far from reality. By using the estimation equation to estimate the probability of occurrence of the lightning hazards, it is also possible to examine whether the lightning withstanding voltage is sufficient.

3.6 Comparison of the result in the case of electrified section with that in the case of the nonelectrified section

According to the statistics, lightning hazards occur 
more frequently in non-electrified sections than in electrified sections. Some say that this is because the electromagnetical energy of lightning is distributed through the signalling equipment and electrical power equipment such as overhead lines and feeder lines installed in electrified sections. Figures 6 and 7 should be referred to in order to verify this inference. Figure 6 compares overvoltage generated in a rail in a non-electrified section (details are given in reference [1].) and in a rail in an electrified section. Figure 7 compares overvoltage generated in the signal cables of an electrified section and a non-electrified section. The lines shown in Figs. 6 and 7 are first order equations whose slope is the average of " $V /(I / r)$ " for each situation and whose intercept is 0 . The result of a two-sided t-test whose significance level is 5\%, showed that there is no statistically significant difference between the average of " $V /(I / r)$ " in electrified sections and non-electrified sections either for rails or signal cables. This means that under the same lightning conditions, the value of the lightning overvoltage is nearly the same regardless of whether it is in an electrified or non-electrified section. This result implies that the existence of the electrical power systems for trains may have nothing to do with the value of lightning overvoltage and the frequency of lightning hazards.

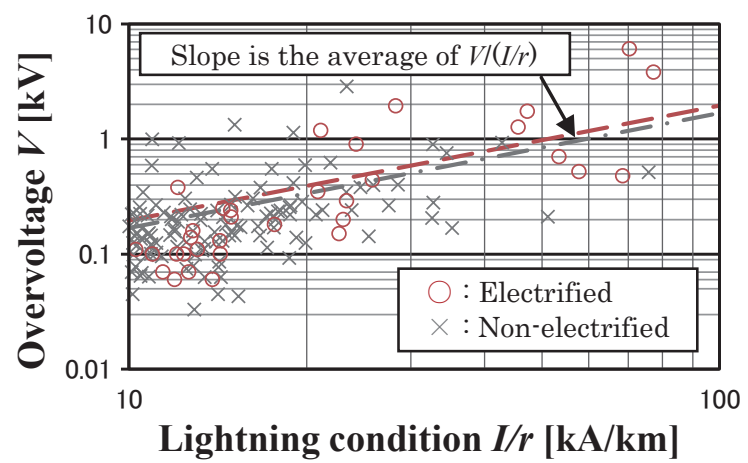

Fig. 6 Comparison of the overvoltage generated in the rails

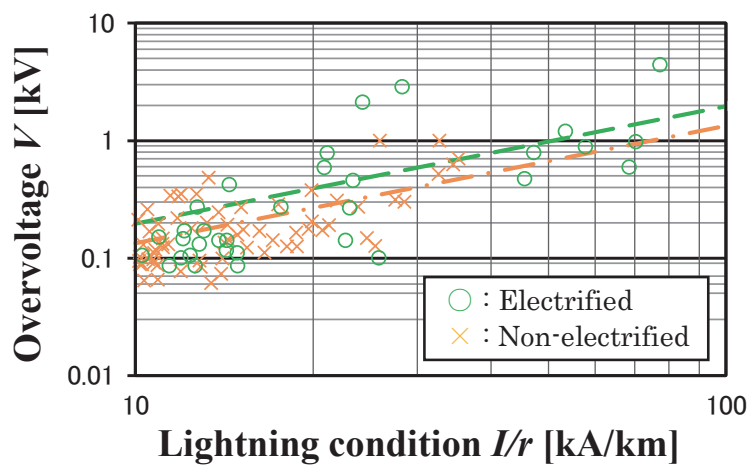

Fig. 7 Comparison of the overvoltage generated in the signal cables

\subsection{Comparison of the ground voltage with the line voltage}

The line voltage was calculated from the waveforms of the ground voltage for a signal cable with 4 cores and a track consisting of 2 rails.
Figure 8 shows the correlation between the ground voltage and the line voltage of the cores in the signal cable and the rails. Using the data in Fig. 8 the percentage of the line voltage to the ground voltage was calculated and is shown in Fig. 9. Figure 9 reveals a variation, from $6.45 \%$ to $115 \%$. The percentage tended to be low when the ground voltage was high. This suggests that it is more important to try to decrease the ground voltage than the line voltage as an effective countermeasure against lightning damage.

Figures 8 and 9 also indicate that the line voltage generated in the rails tended to be higher than in the signal cables. The distance between two rails is greater than between the cores in a signal cable. The electromagnetical equilibrium of the two rails is therefore much lower than in the cores of the signal cable, which may cause higher line voltage in the rails.

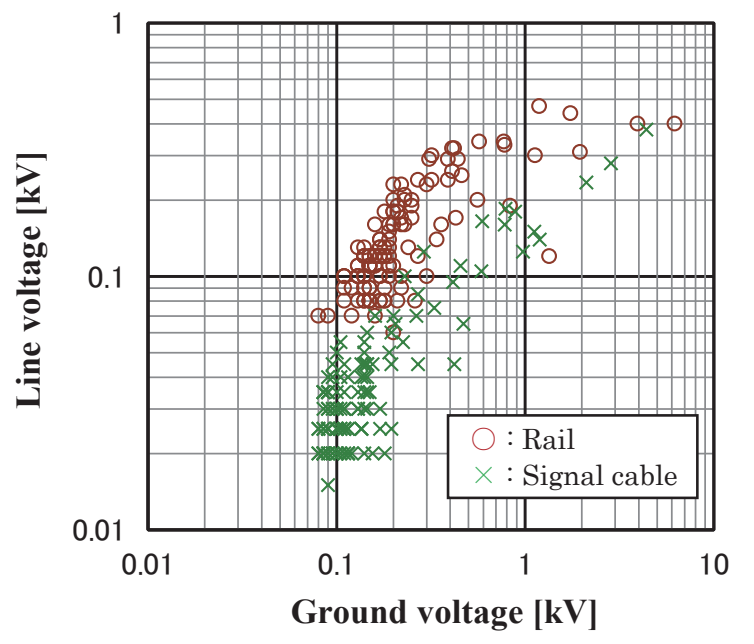

Fig. 8 Correlation between ground voltage and line voltage

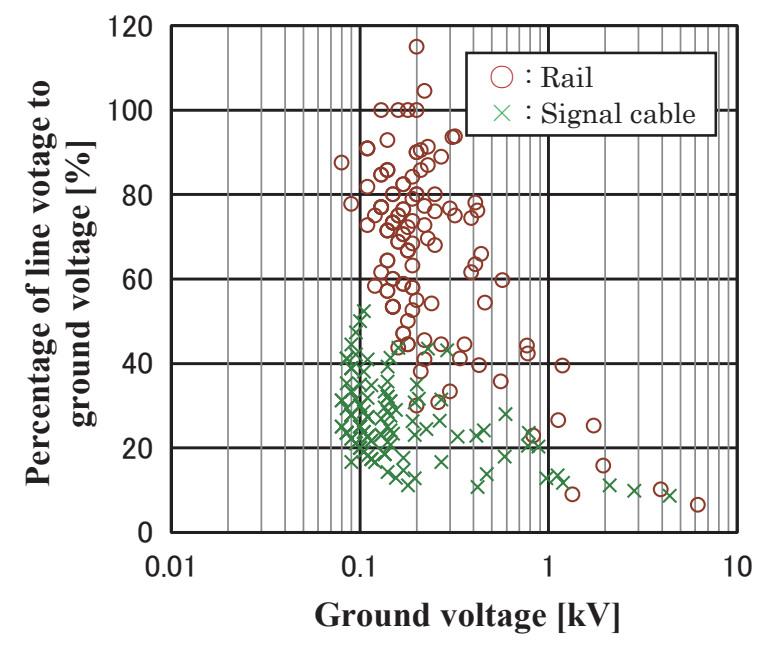

Fig. 9 Percentage of line voltage to ground voltage

\section{Conclusions}

By observing lightning overvoltage (ground voltage) generated by actual lightning striking rails, cables and power lines, the correlation between the lightning condition and the lightning overvoltage was investigated. 
Based on this correlation, equations were formulated for estimating lightning overvoltage based on a set of lightning conditions. The equations made it possible to estimate the lightning conditions which cause lightning hazards, the probability of occurrence of such a hazard and the number affecting signalling equipment. Based on this estimation, it is also possible to examine the maximum allowable voltage generated in signalling equipment from lightning and the effect of countermeasures for decreasing these hazards. This paper also clarified that the line voltage tends to be much lower than ground voltage; as such, it is important to try to decrease ground voltage for countermeasures to be effective against lightning damage.

The authors compared results of lightning voltage observations on an electrified and a non-electrified railway. Under the same lightning conditions, the value of the lightning overvoltage is nearly the same regardless of whether the section is electrified or not. This result implies that the existence of the electrical power systems for trains may have nothing to do with the value of the lightning overvoltage and the frequency of lightning hazards. More study is needed.

Now, in order to analyze the lightning overvoltage in various cases, there is a plan to execute computer simulations of the electromagnetic phenomena generated in railway equipment. After having established a method for this simulation, the result of this research will be utilized to increase the accuracy of simulation.

\section{Authors}

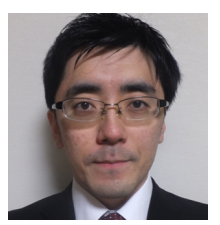

Yuto $O N O$

Assistant Senior Researcher, Signalling

Systems Laboratory, Signalling and Transport Information Technology Division

Research Areas: Lightning Protection

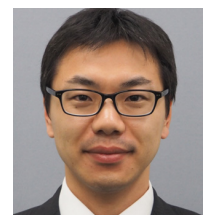

Takuya NOMURA

Researcher, Signalling Systems Laboratory, Signalling and Transport Information Technology Division Research Areas: Track Circuit, Image Recognition

\section{Acknowledgement}

The authors acknowledge the great support provided by the Electrical Technology Research Office of West Japan Railway Company in carrying out this research.

\section{References}

[1] Ono, Y., Arai, H., and Sugimoto, K., "Methodology to Estimate Lightning Risk for Railway Signalling Systems," presented at the 10th World Congress on Railway Research, Sydney, Australia, November 25-28, 2013, ID 106.

[2] Sekine, Y., Ametani, A., 「分布定数回路論 (Distributed Constant Circuit Theory)」CORONA PUBLISHING CO., LTD., pp. 135-136, 1990 (in Japanese).

[3] Rakov, V. A. and Uman, M. A., Lightning Physics and Effects. Cambridge University Press, pp. 159-161, 2003.

[4] Saito, M., Ishii, M., and Sugita, A., "Comparison of directly measured current and JLDN data associated with lightning strokes hitting Tokyo Skytree," presented at the 23rd International Lightning Detection Conference and the 5th International Lightning Meteorology Conference, Tucson, Arizona, USA, March 1821, 2014.

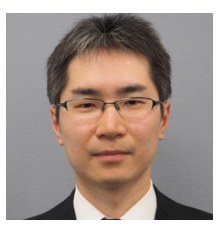

Hiroyuki FUJITA

Assistant Senior Researcher, Signalling Systems Laboratory, Signalling and Transport Information Technology Division

Research Areas: ATP, Deterioration of Electronic Device

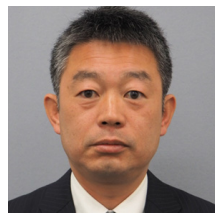

Hideki ARAI, Ph.D.

Laboratory Head, Signalling Systems Laboratory, Signalling and Transport Information Technology Division Research Areas: Lightning Protection, ATP 